\title{
LAS INSEGURIDADES DEL RETORNO: VIAJES DE VUELTA Y LAS VUELTAS DE LOS VIAJES
}

\section{RETURNING UNCERTAINTIES: RETURN JOURNEYS AND TRAVEL CIRCUMSTANCES}

Eleder Piñeiro Aguiar Universidad San Gregorio de Portoviejo. Ecuador/Ecuador elederpa1983@gmail.com

Manuel Ferrer Muñoz

Pontificia Universidad Católica del Ecuador, Sede Ibarra. Ecuador/Ecuador ferrermuma@gmail.com

Recibido/Received: 20/01/2015

Modificado/Modified: 16/04/2015

Aceptado/Accepted: 29/04/2015

\section{RESUMEN}

Las migraciones son parte consustancial de la globalización y, por tanto, construyen formas de entender la relación 'nosotros-otros' en un plano de ampliación de la ciudadanía. Comprender un fenómeno como el del retorno migrante resulta clave a la hora de analizar la gobernabilidad global, las expectativas ante el sistema capitalista o las capacidades de los imaginarios para explicar las migraciones. Con estas líneas se trata de problematizar un concepto en constante construcción académico-política, como es el del retorno, para relacionarlo con la seguridad ciudadana y las relaciones entre minorías y mayorías.

\section{PALABRAS CLAVE}

Retorno, hogar, seguridad, migraciones.

\section{SUMARIO}

1. Introducción: lo que la migración dice al hogar. 2. La dificultad de definir el retorno. 3. Sobre la seguridad del retorno y de la migración. 4. Conclusiones. Bibliografía.

\begin{abstract}
Migrations are inseparable from globalization and therefore they create ways of understanding the "usothers' relationship on the ground of an extension of citizenship. When analyzing the global governability the expectations, facing the capitalist system or the imaginary explaining migrations, are crucial to understand such a phenomenon as the return migration. This work is about bringing forth as controversial a concept that is in a constant construction academically and politically such as the concept of return, in order to relate it with public security and the relationships between minorities and majorities.
\end{abstract}

\section{KEYWORDS}

Return, home, security, migrations. 


\section{CONTENTS}

1. Introduction: What migration tells home. 2. Difficulties and problems in defining 'return'. 3. About security of return and migration. 4 . Conclusions. References.

\section{INTRODUCCIÓN: LO QUE LA MIGRACIÓN DICE AL HOGAR}

Según el antropólogo peruano Teófilo Altamirano (2000), los imaginarios constituyen construcciones culturales inherentes a todos los migrantes, en las que intervienen componentes racionales e irracionales, objetivos y subjetivos, reales, que inciden sobre el migrante antes y después de la emigración. Son ideales que les acompañan a lo largo de su ciclo vital (Goycoechea y Ramírez, 2002).

Cabría considerar, a modo de hipótesis, que, en el caso de las migraciones transnacionales, intervienen algunos elementos en la construcción de imaginarios e imágenes colectivas que apuntalan la decisión migratoria. Dichos factores vienen determinados por los medios de comunicación, los relatos de los familiares en el exterior, la existencia de redes sociales... o son producciones que elabora el mismo sujeto durante el proceso migratorio. Metáforas, retóricas, expectativas, ilusiones y deseos se asemejan, aunque en otro sentido (unos de ida, otros de vuelta) a los que Alfred Schutz describe en su reflexión sobre 'la vuelta a casa del veterano de guerra'. El imaginario en torno al hogar genera ciertas percepciones subjetivas y nos habla de un espacio que se transforma, en la medida en que el migrante tamiza esa realidad a través de sus propias percepciones. En consecuencia, aquello que se entiende por hogar varía con la experiencia de estar fuera. Así, a la vuelta ya no es lo mismo, aunque se pretenda: la búsqueda de ese porqué nos lleva a concluir que la diversidad de rutinas origina modos diferentes de comprensión del hogar. "Quien marcha del hogar ingresa en otra dimensión social; ya no le es dado vivir en presente el marco social representado por el hogar: al abandonarlo ha reemplazado esas experiencias vividas por recuerdos, que mantienen vivo solamente lo que la vida en el hogar significaba hasta el momento en que él le dejó" (Fuente, 2003: 157).

Según explica José Castillo (en Izquierdo Escribano y Álvarez Silvar, 1997: 41), Schutz se posiciona ante el retorno del emigrante como frente a la historia de un doble desarraigo: extraño en el lugar de destino, verifica con dolor a su regreso al hogar que nadie es profeta en su tierra y que retornar viene a significar, a fin de cuentas, emigrar dos veces. No en vano, el fenomenólogo alemán trae a colación la vuelta de Ulises a su tierra, Ítaca, que se le muestra en un primer momento como desconocida. El regreso al cabo de veinte años -esa mítica peripecia de ida y vuelta del héroe de la guerra de Troya-, constituye el arquetipo y canon de la literatura de viajes. Ítaca es agreste, fea, árida, "pero es mi hogar" -nos recuerda el "varón de multiforme ingenio": y resulta imposible hallar nada más dulce que la propia patria, pues el hogar representa mucho más que algo físico o geográfico: es una percepción, una imagen, algo sensorial y vivido que se graba en la mente y se corporaliza e incorpora, creando una subjetividad y un extrañamiento que acompañarán a lo largo de toda la vida. Por eso la triste suerte del poeta que muere lejos del hogar, cuyos restos cubre el polvo de un país vecino, que Antonio Machado cantó anticipándose a su propia peripecia personal.

Un lugar donde no se ha estado, que se conoce sólo de oídas, puede servir de acicate al impulso para emprender la marcha, aunque no llegue a revestirse de los caracteres de El Dorado. Basta el estímulo de lo que Riesman denomina la 'moral de radar', con el consiguiente 'efecto demostración' subsiguiente a los ostentosos alardes de los que 
alcanzaron la fortuna de regresar ricos y acaudalados (Fuente, 2003: 151-152). Ésos son los presupuestos en que se funda Josebe Martínez para describir, con desbordante riqueza de detalles, cómo el deseo de aventura influyó en la colonización de América (Martínez, 2010: 56).

De ese momento iniciático que generó todo un imaginario se derivó otro, con el paso de los siglos: el de la Madre Patria, título que se aplicaba a España como modelo referencial. Existe, incluso, un mito en torno a la migración, que la presenta como una especie de 'vuelta a las raíces', pues los elementos culturales compartidos colaboran en la percepción del viaje como algo necesario que ha de realizarse alguna vez en la vida. Ese anhelo metaforiza todo un océano como un simple 'charco' -expresión que hallamos ya documentada a principios del siglo XX, en el Diccionario de argot español de Luis Besses (1905)- que se cruza o ha de cruzarse alguna vez. De hecho, uno de los planes de retorno elaborados por el Gobierno de Argentina en los primeros años de este siglo -los posteriores al denominado 'Corralito'- para recibir a sus migrantes llevaba dicho nombre: 'Raíces': y no perdamos de vista la especificidad argentina, de cuyas gentes decía con sarcasmo y una pizca de provocación José Luis Borges, aludiendo a los intensos flujos migratorios de los siglos XIX y XX, que descendían de los barcos.

En relación con las identidades nacionales resulta clave la obra de Benedict Anderson (1983), que, por medio del concepto de 'comunidad imaginada', revela la incidencia de la prensa y de la educación escolar en los procesos de conformación de las naciones europeas y americanas. Uno de los ejes claves de la modernidad viene proporcionado precisamente por el hecho de que personas que habitan espacios geográficos alejados entre sí puedan sentirse formando parte de algo común, que, al proporcionarles unas señas de identidad, las distingue y separa de otras colectividades nacionales. Acierta, pues, Luis Carlos Castillo (2009: 19) cuando, en continuidad con Anderson, sostiene que la nación constituye un artefacto cultural que ha sido inventado y producido en buena parte por las elites intelectuales con el desarrollo de la modernidad, sin que esa condición de 'inventado' o 'imaginado' se equipare a una ilusión que la prive de realidad tangible. La conciencia del 'nosotros', que implica la consideración del 'otro' como grupo al que no pertenecemos, deriva de un artificio que logra el efecto de que individuos inconexos compartan el sentimiento de un proyecto común. $Y$ esa comunidad imaginada se halla en la base de los diversos nacionalismos desarrollados en el marco del moderno sistema capitalista que, al mismo tiempo, demanda una creciente mano de obra -imprescindible para sostener la civilización tecnológica- y exige la contratación de trabajadores foráneos (Fuente, 2003: 149-150) que, de modo inevitable, serán conceptuados como integrantes de la 'otredad'. No parece que sea el caso de repetir aquí las ideas expresadas en un libro de próxima publicación, donde uno de los autores de este artículo plantea que el concepto de nación $\mathrm{o}$, si se quiere, la conciencia de pertenencia a una misma comunidad mediante la construcción de una identidad basada en un imaginario común, resulta difícilmente aprehensible, por su misma opacidad, y que sobre ese fondo generalizante del 'imaginario nacional' se proyectan imágenes que acaban por sustituir a la cosa misma y erigirse como lo genuino.

Una nación es, por lo tanto, una solidaridad a gran escala, constituida por el sentimiento de los sacrificios que se han hecho y de aquellos que se está dispuesto a hacer. Presupone un pasado; sin embargo, se resume en el presente mediante un hecho tangible: el consentimiento, el deseo claramente expresado de continuar una vida en común (Renan en Bhabha, 2010: 36). 


\section{LA DIFICULTAD DE DEFINIR EL RETORNO}

Lo que para unos constituye una migración, para otros es retorno, y esto nos enfrenta a una de las primeras dificultades con que tropezamos al tratar de conceptualizar correctamente el término. El retorno encierra, además, un fuerte componente simbólico y emocional que dificulta su teorización. De otro lado, el carácter más o menos voluntario del retorno experimenta variaciones según el contexto geopolítico en que se produzca. A lo anterior se suma, en fin, el hecho de que existen migraciones sucesivas, que comportan una especial significación para la persona que se desplaza.

Con el análisis del retorno entramos en un nuevo campo comparativo, en el que no sólo intervienen el que ha emigrado y el que no, sino también quien quiere (y puede) retornar y quien no. Además, la diversidad de circunstancias de los migrantes introduce determinaciones cruciales de los viajes, que se revisten de una variada gama de prácticas materiales y espaciales, generadoras de efectos muy diversificados, y provocan la emergencia de culturas diaspóricas (Clifford, 1999: 51).

La definición de las Naciones Unidas de retorno, que se remonta a 1998, compartida de modo casi unánime por los estudiosos de la materia (Heredia y Ortega, 2014: 146), suscita también ciertos problemas, pues remite al país de origen cuando al menos en ciertos casos sería más apropiado hablar de país de nacimiento, porque las experiencias y la duración de los primeros años de socialización marcan la personalidad y condicionan la visión que se posee del país propio. Por otro lado, existen diferentes 'lugares' en un 'país', por lo que la definición subjetiva del posible retornado, que se identifica con uno u otro rincón, y quizá sólo con él, enreda aún más la teorización del retorno. En efecto, existen poblaciones que reivindican su autonomía o apuestan por una soberanía diferenciada de la que corresponde al Estado a que pertenecen; y encontraremos también a personas -pueblos originarios, poblaciones en diáspora, minorías de un Estado, etcétera- cuyo marco espacial de referencia se restringe a un ámbito más estrecho (entes administrativos subordinados al estatal).

A ello se suma un problema asociado al inicio mismo del desarrollo de las ciencias sociales: la especial relevancia que se da a las migraciones internacionales, en detrimento de las migraciones interiores. Con la formación del sistema capitalista moderno surgieron también los Estados-Nación, que buscaban satisfacer la necesidad de disponer de aparatos administrativos e impositivos acordes a las exigencias de los diferentes territorios integrados en un mismo marco político, y separados de otros Estados nacionales por fronteras que se querían impermeables. El conteo estadístico y la seguridad interna y externa fueron de la mano, al tiempo que la ciencia estadística se convirtió en un mecanismo clave al servicio de la soberanía estatal.

De lo expuesto hasta aquí cabe concluir que contabilizar el 'retorno' de migrantes transnacionales no significa ni mucho menos que se esté tomando en consideración todo el retorno, pues las experiencias, las prácticas, los discursos y el cómputo de quienes traspasan fronteras 'locales' son también factores determinantes en la dinámica demográfica de cada país. Eso sin contar con que lo que por algunos es considerado como frontera para otros se trata tan sólo un territorio donde transcurre su vida cotidiana. El viaje, en suma, no es una simple consecuencia sino que ha de ser entendido en un plano holístico: "¿qué pasaría si el viaje fuese visto sin trabas, como un espectro complejo y abarcador de las experiencias humanas? La práctica de desplazamiento podría aparecer como constitutiva de significados culturales, en lugar de ser su simple extensión o transferencia" (Clifford, 1999: 13).

El análisis del retorno, más allá de la indagación de una práctica de viaje, proporciona una oportunidad para un acercamiento a las relaciones sujeto-objeto, campo fecundo de discusión 
en diversas disciplinas científicas, por las enconadas polémicas que suscita, asociadas a la compleja reflexión acerca de los límites entre objetividad y subjetividad en cuanto constructoras de la ciencia, que se remontan a la Ilustración, cuando Kant destacó el definitivo papel del sujeto en la constitución del objeto.

Para ejemplificar la diversidad de matices con que puede ser enfocado el fenómeno del retorno bastaría recordar el amplio arco de opiniones en torno a la equivocada identificación que los aztecas establecieron entre Cortés y el regreso de Quetzalcóatl -un error que Miguel León Portilla (2007) calificó de trágico, por cuanto inhibió la capacidad de resistencia de los mexicas-, que permite concluir que el análisis del retorno se halla mediatizado por las premisas mentales que se adopten como referencia.

En todo caso, la configuración del mundo actual, proclive al reforzamiento de las barreras fronterizas ante el generalizado temor a las inmigraciones masivas de indocumentados, comporta el riesgo de convertir en exóticos determinados destinos, exacerbar los nacionalismos y, finalmente, reforzar la tendencia a la esencialización de las culturas, como si éstas constituyeran algo opaco y homogéneo: pues, en verdad, resulta más que cuestionable atribuir a un territorio determinado la posesión de una 'esencia' susceptible de ser aprehendida intelectual o afectivamente, cualquiera que sea su status administrativo, configurado como Estado o en la condición de parte integrante de un cuerpo estatal más amplio. Tales planteamientos, cada vez más extendidos, conducen a desdeñar la diversidad, la porosidad y las influencias mutuas entre unos y otros grupos sociales dotados de culturas diferentes.

Otro enfoque del retorno consiste en promover indagaciones sobre los conocimientos y las experiencias adquiridos por el emigrante que retorna, que cabe tipificar como un exponente destacado de lo que García Canclini (2001) denomina una 'cultura híbrida'. Hablar en términos de hibridación supone repensar el concepto de identidad, pero también superar ciertos dualismos, como el de sociedad de origen / sociedad de destino. En cuanto a la definición de ese concepto, cedamos la palabra al propio García Canclini:

"Entiendo por hibridación procesos socioculturales en los que estructuras o prácticas discretas, que existían en forma separada, se combinan para generar nuevas estructuras, objetos y prácticas. A su vez cabe aclarar que las estructuras llamadas discretas fueron resultado de hibridaciones, por lo cual no pueden ser consideradas fuentes puras" (García Canclini, 2001: 14).

En las relaciones interculturales existen elementos más aptos para 'hibridarse', mientras que otros ni siquiera logran entrar en contacto. Además hay que precisar qué se integra, por parte de quién y en qué condiciones (de asimetría o de igualdad). Así, la música y la gastronomía (al menos en algunas vertientes) resultan propicias para sincretizarse; mientras que las costumbres y las tradiciones de parentesco tropiezan con más reticencias.

Existe una coincidencia bastante extendida entre los estudiosos sobre el reconocimiento de la dificultad terminológica y de las imprecisiones históricas de la definición de 'retorno', que sólo hoy en día empieza a cobrar un lugar destacado en las investigaciones sobre la migración, aunque no se disponga todavía de un cuerpo teórico propiamente dicho: más bien se utilizan metodologías de análisis, escuelas y disciplinas propias de la migración, que se trasladan y se aplican al tratamiento del retorno. Así lo aprecia Antonio Izquierdo, cuando muestra el contraste entre las ópticas con que se analiza este fenómeno: "al retorno de los emigrantes se le somete tanto al análisis grosero de tipologías ad hoc como al más refinado de tipologías sistemáticas" (Izquierdo Escribano y Álvarez Silvar, 1997: 37). También concuerdan los especialistas en la quiebra que implica el retorno en las explicaciones 
habituales del pretendido carácter definitivo de la migración, máxime en el caso de las políticas públicas de control de los flujos migratorios. Se trata, además, de una realidad difícilmente mensurable, ya que los gobiernos se centran más en el cómputo de las entradas que de las salidas del territorio nacional.

Mientras unos teóricos adoptan como referente principal el tiempo de estancia en la sociedad de recepción (por ejemplo, King), otros se centran en las causas: posición ésta adoptada por Cerase en sus análisis de la emigración italiana del Mezzogiorno. A este respecto Jorge Durand (2004) establece una tipología muy detallada que distingue entre retorno voluntario del migrante establecido, retorno del migrante temporal, retorno transgeneracional, retorno forzado, retorno del fracasado y retorno programado. De todos modos, este acercamiento terminológico proporciona sólo cierta claridad analítica para casos tipificados. El retorno, como la migración, se resiste al encasillamiento y a la pretensión de conceptuarlo como algo definitivo y unicausal.

\section{SOBRE LA SEGURIDAD DEL RETORNO Y DE LA MIGRACIÓN}

En la medida en que el retorno constituye una realidad cambiante, no sujeta a una praxis prefijada, su mera presencia y difusión generan ambigüedades y siembran inquietudes. La movilidad se percibe como un factor de riesgo, como una práctica que, en cualquier momento, es susceptible de poner en jaque al sistema, al Estado, a la comunidad internacional. Para controlar la movilidad internacional y prever posibles amenazas a ella asociadas, surgen y se desarrollan los mecanismos de seguridad. Por eso se han reforzado las normativas migratorias, los controles de las aduanas y los sistemas de seguridad en los aeropuertos, a fin de prevenir futuros desastres. Así reza, al menos, el discurso político. En consecuencia, la frontera se endurece y se multiplica para garantizar la seguridad. Ya no se trata sólo de una línea divisoria: adquiere un formato capilar, nodal, y fiscaliza y somete a un complejo sistema de control a cada viajero en tránsito.

También encontramos manifestaciones de esa mirada prejuiciosa en el plano del lenguaje, pues no existen palabras neutras: todas poseen alguna carga semántica. Además, más allá de las fronteras políticas persiste la del habla. No en vano los griegos consideraban extranjeros bárbaros, 'los que balbucean' - a los que desconocían su lengua: y esa connotación peyorativa del término 'bárbaro' ha llegado hasta nosotros. Cuando de modo coloquial se dice que determinada forma de hablar de una persona daña el oído, se está erigiendo una frontera. En efecto, nos sentimos seguros, en casa, cuando el vehículo de comunicación es la propia lengua, pronunciada tal y como la aprendimos: por eso la incomodidad y el rechazo que puede causar su habla con acentos extraños, que suelen ser denostados o criticados.

Sin embargo, es importante ubicarse en la perspectiva de análisis adecuada: cuando se dice de otro idioma que es 'difícil' se olvida que los que poseen dicha lengua como materna no parecen excesivamente agobiados por su aprendizaje. Más aún, se manejan con soltura en su uso, sin mayores problemas. El repaso de uno de nuestros clásicos del siglo XVIII, Nicolás Fernández de Moratín, constituiría un ejercicio recomendable para quienes incurren en tan desatinada apreciación: "admirose un portugués / de ver que en su tierna infancia / todos los niños en Francia / supiesen hablar francés"...

La pretensión de seguridad (ante la incertidumbre) busca prever la emergencia, tratando de anticiparse a acontecimientos que están por venir; y realiza simulacros: implanta controles en el aeropuerto, organiza redadas aleatorias, fetichiza los papeles, emplaza en colas interminables a los migrantes..., sin tener en cuenta la característica axial de dicho simulacro 
(su condición de copia de algo que no existe). Y es que la inseguridad no puede pronosticarse a causa de las potencialidades infinitas que abre la creatividad humana.

En las fronteras, que se han tornado porosas, efímeras, cambiantes, se multiplican los filtros para afianzar la seguridad. El FRONTEX (Agencia Europea para la Gestión de la Cooperación Operativa en las Fronteras Exteriores) o los dispositivos SIVE (Sistema Integrado de Vigilancia Exterior) proporcionan elocuentes ejemplos de los mecanismos de defensa de que se dota la auspiciada 'Europa Fortaleza'. E incluso se llega más lejos, al convertirse a los ciudadanos en dispositivos complementarios de control, por medio de normativas de extranjería que catalogan como delito la acogida a 'irregulares'; o imponiendo a los médicos una dramática conculcación del juramento hipocrático, al exigírseles la denegación de la atención sanitaria a quienes carezcan de documentación en regla. Tal vez haya que preguntarse si hay sincera voluntad política de los países miembros de la Unión Europea de facilitar el proceso de integración ciudadana a los inmigrantes. Y parece que no, al menos en España: porque, si la hubiera, ¿cómo explicar la ineficacia de la gestión administrativa, el escandaloso retraso de los trámites, la desproporción entre el cuantioso gasto contemplado en la partida de controles fronterizos y las irrelevantes cantidades invertidas para ofrecer oportunidades de trabajo y de vivienda a los que vienen de fuera?

La tan cacareada crisis económica sirve de marco y de excusa para instrumentar nuevas formas de regulación para los flujos migratorios. Y, junto a ella, opera un criterio clave para la toma de decisiones: el principio de exclusión, que invisibiliza a minorías; auspicia la desaparición de pueblos enteros 'no asimilables' por medio de genocidios y etnocidios; impone expulsiones según criterios de nacimiento; conduce al ostracismo a millones de individuos que simplemente han nacido "al otro lado de la raya". En muchos casos, la simple ambivalencia inquieta al sistema. En el migrante -y más el que retorna-, el 'síndrome de Ulises' -tal y como ha sido denominado por algunos psicólogos-, reúne señales tan contradictorias como la sensación enfermiza de no sentirse de un lado ni del otro; la conciencia de 'ser de aquí y de allá' -la zona gris que no acaba de colorearse, el In-Between de que habla Bhabha-; la perplejidad derivada de sentirse 'un ente' -como gráficamente apuntaba un uruguayo a quien se entrevistó-; el ser llamado 'gallego' en el Río de la Plata y 'sudaca' cerca del Río Miño. No deja de ser relevante a este propósito que los últimos textos de R. L. Stevenson, redactados en Samoa, la soñada isla del Navegante donde murió apenas cinco años después del feliz desembarco en Nuka-Iva, versaran precisamente sobre su Escocia natal.

Si nos remontamos centurias atrás, cuando se emprendieron los primeros pasos de los españoles en tierras americanas, y tratamos de adentrarnos en las mentes de conquistadores y conquistados, apreciaremos que, como inteligentemente puso de manifiesto Uslar Pietri, la entrada en contacto, de modo abrupto, de dos visiones del mundo tan distantes como las que poseían unos y otros determinó en todos ellos transformaciones de hondo calado. "Al día siguiente del descubrimiento de América, irremediablemente, el español ya no pudo seguir siendo el mismo que era, pero el indio americano tampoco" (Uslar Pietri, 2002: 89). La consagración del término 'indiano', con el que pasaron a ser conocidos los españoles que regresaban a su tierra después de haber residido unos años en América, viene a ser una forma de reconocimiento de las profundas transformaciones que habían experimentado sus vidas (Uslar Pietri, 2002: 132-133).

Si en la Grecia de Ulises la palabra extranjero contenía a la vez aspectos negativos (el foráneo trae suciedad y desorden, por lo que debe ser ritualizado, sacralizado; constituye una amenaza y puede propagar enfermedades, como nos recuerda Mary Douglas), y positivos 
(noticias, nuevas técnicas, ideas, conexiones con el exterior), en los albores del siglo XXI priva casi en exclusiva la cautelosa primera vertiente. Ambivalencia del extranjero y ambivalencia del migrante: Ulises que, por fin, torna a casa. Por eso, algunas teorías psicológicas aluden al 'síndrome del héroe' que encarnan algunos migrantes, porque, una vez adoptada la decisión de migrar, se está obligado a asumir todas las consecuencias: envío de remesas a la familia y a quienes facilitaron los medios económicos para el viaje; sustento de los miembros del entorno familiar más cercano, que los acompañan en su periplo viajero; acreditarse como dignos del reconocimiento de quienes los vieron nacer y partir, que los han convertido en símbolos de éxito y de arrojo. La condición de héroe comporta, además, un digno silencio y una estoica compostura ante la adversidad. Y todo ello sin esperanza cierta de volver: privilegio éste reservado a unos pocos, como aquellos indianos exitosos que hacían las Américas a finales del siglo XIX, que inspiraron piezas musicales tan notables como Los Gavilanes.

Porque las minorías a que dan lugar esos movimientos migratorios son emplazadas por las políticas al uso como sujetos que ocupan una zona intermedia entre los individuos y la humanidad en general, y puesto que el azar que impregna sus decisiones de mudanza o de permanencia resulta impredecible, la acción de los gobiernos se orienta a preservar y encapsular el fenómeno de los que han incursionado desde fuera. Se trata de encorsetar la futura excepción y de crear identidad en torno a un tiempo futuro que se quiere libre de la amenaza potencial que representan los de afuera. Al confundirse integración con asimilación, se quiere 'incluir' a las minorías para que la sociedad se sienta segura, sin reparar en que la clave de esa tranquilidad radica más bien en la 'convivencia'.

Para entender mejor el modo en que se enfoca el tratamiento de las minorías, conviene observar la trayectoria que, en la ciencia sociológica, caracterizó a la Escuela de Chicago, pionera en estudios sobre migración y antropología de la ciudad, que acuñó el concepto de 'desatención cortés': un estado de ánimo hacia lo foráneo que, sin llegar a resultar insultante, proponía alcanzar un cierto grado de 'pasotismo' como señal indicadora de la perfecta inclusión. Dicho de otro modo: la clave del éxito que evidenciaba una satisfactoria adaptación al sistema radicaba en no suscitar demasiada atención, en pasar inadvertido. Lo mejor era no dar que hablar, no hallarse en boca de nadie.

En los tiempos que corren se experimenta, además, la constante necesidad de que el que vino de fuera demuestre de modo permanente su inocencia: con papeles, con un puesto de trabajo ajeno a la economía sumergida, con una vivienda 'digna' y unos certificados bancarios satisfactorios... La tranquilidad, la rutina y la familiaridad son significativos de una correcta adecuación entre autóctonos y foráneos y generan sentimientos de seguridad. ¿Importa lo que los otros digan? Sí, y mucho. Goffman, desde teorías interaccionistas, afirma que la identidad no se construye solo desde aquello que nosotros asumimos, sino además teniendo en cuenta lo que otros opinan y lo que nosotros pensamos que ellos piensan. La interrelación de la alteridad y la identidad genera relaciones, en muchos casos asimétricas, que deben ser constantemente negociadas. En la construcción de la sociedad cívica que se sustenta en los nexos de unión entre extranjeros y autóctonos intervienen la conformación de una opinión pública en torno a los migrantes y las políticas migratorias. Estos ejes (opinión, normativa, sociedad cívica) se imbrican mutuamente, y el principio de seguridad se configura como axial para los tres.

En tanto que la seguridad se presenta como un logro objetivo, la integración es considerada como una aspiración subjetiva, que presupone la aceptación por el migrante de los rasgos configuradores de la sociedad de acogida y la exigencia no declarada -pero insinuada de mil formas- de que no sean 'demasiados' (una estimación subjetiva también). 
En nombre de la seguridad, los poderes políticos mantienen a los migrantes en perpetua zozobra, mediante la continua y sistemática exigencia de documentos que, una vez y otra, han de ser actualizados. Por eso no faltan autores que hablan del 'fetichismo de los papeles' (Suárez-Navaz, 2007) que, en realidad, prometen mucho más de lo que aportan una vez obtenidos. Esa desagradable sensación de 'estar toda la vida resolviendo papeles' emplaza al migrante en subjetividades nuevas ante el poder estatal -cuerpo migrante vs cuerpo del Estado-, que ha analizado Didier Fassin (2003) en su descripción de la búsqueda de una biolegitimidad. En efecto, el desasosiego ante la complejidad que entraña el logro de dichos papeles y la conciencia de que los nacionales viven ajenos a esa pesadilla recurrente se hallan presentes de continuo en los proyectos migratorios, una vez alcanzados sus destinos.

\section{CONCLUSIONES}

Si de algo cabe entera certeza, es que todo es susceptible de empeoramiento. Y cualquiera de nosotros puede eventualmente convertirse en migrante y afrontar, en consecuencia, los retos consiguientes a esa condición. En cierta manera, ya hemos asumido ese papel, como señala Sandro Mezzadra (2005) cuando se refiere al devenir migrante de las sociedades posmodernas. Y tratamos de sentirnos confiados, aun a sabiendas de que apenas existen espacios de confianza: como lo expresa Bauman en sus metáforas líquidas, los archipiélagos de seguridad son cada vez más visitados por náufragos extranjeros.

En lo que al movimiento migratorio de vuelta se refiere, es preciso asumirlo como un devenir susceptible de múltiples explicaciones; sujeto a cambios inesperados en las condiciones de vida en origen, tránsito y destino; afectado por muy diversos condicionantes culturales y materiales, etcétera. Sí queda fuera de toda duda -y así lo consigna Durand, cuando explica la 'mitología en torno al retorno'-, que "los migrantes no queman premeditadamente las naves", en abierto contraste con los aqueos que, ante la muralla de Troya, rompieron sus embarcaciones para cancelar la opción de un paso atrás: vencían la guerra o no regresaban al hogar; o, ya en el siglo XVI, con Hernán Cortés, que mandó hundir las naves que condujeron a él y a sus hombres desde Cuba, a poco de tocar tierra en Yucatán, antes de partir hacia el interior del país y emprender la conquista de lo que más tarde sería la Nueva España. Muy otra es la mentalidad de los migrantes, analizada por Durand: "lucharemos pero si algo sale mal, habrá naves que permitan el regreso".

Abierta siempre la opción de retornar, las decisiones que se adoptan para ejecutarla son siempre muy medidas y ponderadas y sujetas a la toma en consideración de un sinfín de circunstancias. Por eso, en lugar de plantear el proyecto migratorio como algo acabado y lineal, parece más acertado tratar de procesos migrantes en construcción constante.

\section{BIBLIOGRAFÍA}

ALTAMIRANO, T. (2000). Liderazgo y organizaciones de peruanos en el exterior. Vol. I. Lima: PROMPERU y Fondo Editorial PUCP.

ANDERSON, B. (2006). Comunidades Imaginadas. Reflexiones sobre el origen y la difusión del nacionalismo. México: Fondo de Cultura Económica.

APPADURAI, A. (2001). La modernidad desbordada. Dimensiones Culturales de la Globalización. Buenos Aires: Fondo de Cultura Económica. 
BHABHA, H. (comp.) (2010). Nación y narración. Entre la ilusión de una identidad y las diferencias culturales. Buenos Aires: Siglo XXI.

CASTILLO, J. (1997). "Teorías de la migración de retorno". En A. Izquierdo Escribano, A. y Álvarez Silvar, G. (eds.) Politicas de retorno de emigrantes. A Coruña: Universidade da Coruña, pp. 29-44.

CASTILLO GÓMEZ, L. C. (2009). Etnicidad y nación. El desafío de la diversidad en Colombia. Cali: Universidad del Valle.

CLIFFORD, J. (1999). Itinerarios Transculturales. Barcelona: Gedisa.

DURAND, J. (2004). "Ensayo teórico sobre la migración de retorno. El principio del rendimiento decreciente", Cuadernos Geográficos, 35: 103-116.

-- (2006): "Los inmigrantes también emigran: la migración de retorno como corolario del proceso", Revista Interdisciplinar de Mobilidade Humana (REMHU), año XIV, 26 y 27: 167-189.

FASSIN, D. (2003). "Gobernar por los cuerpos, políticas de reconocimiento hacia los pobres y los inmigrantes en Francia”. Cuadernos de Antropología Social, 17: 49-78.

FUENTE RODRÍGUEZ, Y. M. de la (2003). "La emigración de retorno: un fenómeno de actualidad". Alternativas. Cuadernos de Trabajo Social, diciembre, 11: 149-166.

GARCÍA CANCLINI, N. (2001). Culturas híbridas. Estrategias para entrar y salir de la Modernidad. Barcelona: Paidós.

GOYCOECHEA, A. y RAMÍREZ, F. (2002). "Se fue, ¿a volver? Imaginarios, familia y redes sociales en la migración ecuatoriana a España (1997-2000)". Iconos, enero, 14.

HEREDIA, L. y ORTEGA, A. (dirs.) (2014). Diccionario de Migración y Extranjería. Madrid: LID Editorial Empresarial.

LEÓN PORTILLA, M. (2007). Visión de los vencidos. Relaciones indígenas de la Conquista. México: Universidad Nacional Autónoma de México.

LÓPEZ DE LERA, D. (2010). "Emigración, inmigración y retorno: tres etapas de un mismo proceso". Polígonos, Revista de Geografía, 20: 9-27.

MARTÍNEZ, J. (2010). "Estrema Dura, Mar Tenebroso, Mundus Novus: Amo-Esclavo. El Deseo en la Práctica Descolonial”. En Martínez, J., y Rodríguez, I. (eds.) Estudios Trasatlánticos Postcoloniales. I. Narrativas Comando/ sistemas Mundo: Colonialidad/ modernidad Barcelona: Anthropos, pp. 47-74.

MEZZADRA, S. (2005). Derecho de Fuga. Migraciones, Ciudadanía y Globalización. Madrid: Traficantes de Sueños.

SCHUTZ, A. (1974). Estudios sobre teoría social. Buenos Aires: Amorrortu.

SUÁREZ-NAVAZ, L.; MACIÁ PAREJA, R. y MORENO GARCÍA, Á. (2007). Las luchas de los sin papeles y la extensión de la ciudadanía. Perspectivas críticas desde Europa y Estados Unidos. Madrid: Traficantes de sueños.

USLAR PIETRI, A. (2002). Ensayos sobre el Nuevo Mundo. Madrid: Editorial Tecnos. 


\section{Breve currículo:}

\section{Eleder Piñeiro Aguiar}

Doctor en Antropología, Magíster en Migraciones Internacionales y Licenciado en Sociología por la Universidad de A Coruña (España); Director del Centro de Investigación y editor de la Revista Científica de la Universidad San Gregorio de Portoviejo (Ecuador); Investigador del Equipo de Sociología de las Migraciones Internacionales (UDC, España); Investigador del Proyecto de Investigación "Género, Transnacionalismo y Estrategias Intergeneracionales de Movilidad Social (FEM 2011-26210), dirigido por la Dra. Laura Oso Casas y financiado por el Ministerio de Economía y Competitividad de España; Investigador de la Red de Investigadores sobre Identidades Nacionales.

\section{Manuel Ferrer Muñoz}

Doctor en Filosofía y Letras, Sección de Historia, por la Universidad de Navarra (España), Licenciado en Filosofía y Letras, especialidad de Historias, por la Universidad de Granada (España). Docente a tiempo completo en la Pontificia Universidad Católica del Ecuador, Sede Ibarra, desde enero de 2015; Investigador de la Red de Investigadores sobre Identidades Nacionales; Becario Prometeo en el Instituto de Altos Estudios Nacionales (Quito, Ecuador), desde octubre de 2013 a octubre de 2014. Coordinador general del Centro Europeo de Estudios sobre Flujos Migratorios (Gran Canaria, España), desde 2003 hasta 2013. Investigador Titular "C", Tiempo Completo, en el área de Historia del Derecho, en el Instituto de Investigaciones Jurídicas, Universidad Nacional Autónoma de México (UNAM), desde 1994 hasta 2003. Secretario y director de investigación en el Centro de Estudios de Humanidades (Gran Canaria, España), desde 1990 a 1994. 